\title{
How to Move From Belief to Proof? Articulating the Value of Chronic Disease and Care Management Programs for Adults With Asthma
}

Scientific research has generated a convincing evidence base for showing that the majority of chronically ill patients, including many with asthma or chronic obstructive pulmonary disease, are nowadays not receiving the care they need, because our present models of care delivery are not equipped to effectively and efficiently address their demands. ${ }^{1}$ Moreover, studies have demonstrated that most Western health-care systems are in their current form unsustainable for a future characterized by an increasing human, clinical, and economic burden of respiratory and other chronic conditions. ${ }^{1-4}$

In response to this, health-care organizations have implemented a wide spectrum of chronic disease and care management programs to improve care processes and outcomes while making more efficient use of scarce healthcare resources. The aim of these programs is to transform care of chronic illness from acute and reactionary to proactive, planned, and population-based. This should be accomplished through more effective team care and planned interactions; intensified self-management support bolstered by more effective use of community resources; integrated decision support; and wider and better use of patient registries and other supportive information and communication technology. ${ }^{5}$

Notwithstanding the intuitive appeal of this approach, the current evidence regarding its impact on clinical, human, and economic outcomes is severely limited by the number and quality of the existing studies. Although some studies, ${ }^{6-12}$ have found positive results with regard to some aspects of quality of care (eg, improved disease control, adherence to evidence-based guidelines, and patient satisfaction), results on clinical and economic outcomes remain far below expectations. ${ }^{69}$ Indeed, despite relentless efforts and investments, the enthusiasts behind chronic disease and care programs keep struggling to articulate their overall value to patients, care providers, and payers in terms of "proof" rather than "belief." 5,9

But why is it so difficult to show the added value, if any, of these interventions? Do disease and care management programs simply not work as well as many believed they would? Or have the research efforts made so far been largely inadequate to reveal the true impact of disease and care management programs, whether this be positive or negative?

\section{See the Review Article on Page 878}

This issue of RESPIRATORY CARE features a study by Maciejewski et al, ${ }^{13}$ which indeed shows that there have been only a few well-designed evaluation studies of disease-management programs for adults with asthma. That finding parallels the results of other reviews, including programs for various chronic conditions. Of special interest is the review of Lemmens et al, ${ }^{14}$ which found the methodological quality of asthma disease-management studies particularly poor, compared to evaluations of disease-management programs for other conditions. One of the reasons for this might be that asthma programs are, more often than programs for other conditions, carried out (in part) in a community setting instead of a clinical setting. ${ }^{15}$ This generally complicates the conduct of rigorous randomized controlled trials. ${ }^{16}$ Whereas Maciejewski et al recommend that more randomized controlled trials (RCTs) should be undertaken before recommendations about any particular program are made, Lemmens et al ${ }^{14}$ point out that in organizational research RCTs are often impossible to implement. Therefore, if an RCT is practically impossible, the next best design that minimizes potential bias (internal validity), maximizes generalizability (external validity), and is feasible in practice, should be chosen. This would be a first step to better articulate the value of asthma disease and care management programs in everyday practice. As Maciejewski et al rightly point out, studies with quasi-experimental or otherwise flawed designs (which may also include RCTs) should pay more attention to employing the appropriate statistical techniques to correct for potential biases, for example, caused by not randomizing on patient-level.

Another challenge to demonstrating the value of asthma disease-management programs is choosing the "right" measures to evaluate a program's impact. Since disease-management programs are likely to affect structures, processes, and outcomes of care, all 3 types of indicators should be measured. Only by relating the 


\section{Chronic Disease and Care Management Programs for Adults With Asthma}

changes in structures, processes, and outcomes of care can we understand how a program generates value in terms of effectiveness and/or efficiency of asthma care. ${ }^{17}$ Moreover, indicators should be chosen that are both sensitive enough to detect a change stemming from the program components within the time frame of the study, and are associated with the expected (longer term) changes in outcomes of care. Although that may sound all too obvious, reviews have indicated that in about $40 \%$ of studies on disease-management, including studies of asthma disease management, there was no link between the aims and contents of the programs and the evaluated structure, process, and outcome indicators. ${ }^{17}$

Maciejewski et al ${ }^{13}$ contribute new insight into the structure, process, and outcomes of asthma diseasemanagement programs by providing a detailed account of the specific components of asthma disease-management programs, the providers involved, and the collaboration models used to improve the management and coordination of care. They show that, while the programs' outcomes differed strongly, partly resulting from differences in study design, the process outcomes consistently improved following implementation of asthma disease management, regardless of study design. This robust finding is highly encouraging in a field characterized by differences in methods (eg, study design, measures applied, duration of follow-up, populations studied) and in program content, provider collaboration model, and characteristics of the surrounding healthcare setting and system. ${ }^{18}$

Nevertheless, when faced with the question, "Is there added value from asthma disease-management programs on human, clinical, and economic outcomes of care?" the only answer we can justify today is, "It depends." The effectiveness and cost-effectiveness of any intervention is conditional upon who receives what and under what circumstances, and in the case of asthma disease-management programs we have yet to clearly determine the relationships between those factors. Thus, Maciejewski et al are quite right in their conclusion that current evidence is insufficient to recommend any particular program.

However, considering the mounting health-care costs and the fact that innovative industries and health-care practices are greatly outpacing academic research on disease management, there is an urgent need to determine the potential impact of asthma disease management and care management programs on effectiveness and cost effectiveness, even in the absence of "perfect" clinical and economic data. Validated methods for so doing exist and their application to respiratory disease and care management programs has been published. ${ }^{19,20}$ But empirical and review studies, such as that by Maciejewski et al, on the relationship between the struc- tures, processes, and outcomes of disease and care management, are of utmost importance to effectively "move from belief to proof," as regards the added value of asthma disease-management programs.

Lotte MG Steuten PhD MSc Department of Health Organization,

Policy and Economics

School for Care and Public Health Research Maastricht University Medical Centre

and

Care Innovations Research and Consultancy Maastricht, The Netherlands

\section{REFERENCES}

1. McGlynn EA, Asch SM, Adams J, Keesey J, Hicks J, DeCristofaro A, Kerr EA. The quality of health care delivery to adults in the United States. NEJM 2003;348:2635-45.

2. World Health Organization. Chronic diseases and health promotion. http://www.who.int/chp/en. Accessed May 11, 2009.

3. Wagner EH. Chronic disease management: what will it take to improve care for chronic illness? Eff Clin Pract 1998;1(1):2-4.

4. Institute of Medicine. Crossing the quality chasm: a new health system for the 21st century. Washington, DC: National Academies Press; 2001.

5. Coleman K, Austin BT, Brach C Wagner EH. Evidence on the Chronic Care Model. Health Aff (Millwood) 2009;28(1):75-85.

6. Congressional Budget Office. An analysis of the literature on disease management programs: letter to the honorable Don Nickles. October 13, 2004. http://www.cbo.gov/showdoc.cfm?index = $5909 \&$ sequence $=0$. Accessed May 11, 2009.

7. Weingarten SR, Henning JM, Badamgarav E, Knight K, Hasselblad $\mathrm{V}$, Gano A, et al. Interventions used in disease management programmes for patients with chronic illness - which ones work? Metaanalysis of published reports. BMJ 2002;325(7370):925-932.

8. Ofman JJ, Badamgarav E, Henning JM, Knight K, Gano AD Jr, Levan RK, et al. Does disease management improve clinical and economic outcomes in patients with chronic diseases? A systematic review Am J Med 2004;117(3):182-192.

9. Mattke S, Seid M, Ma S. Evidence for the effect of disease management: is \$1 billion a year a good investment? Am J Manag Care 2007;13(12):670-676.

10. Adams SG, Smith PK, Allan PF, Anzueto A, Pugh JA, Cornell JE. Systematic review of the chronic care model in chronic obstructive pulmonary disease prevention and management. Arch Intern Med 2007;167(6):551-561.

11. Norris SL, Nichols PJ, Caspersen CJ, Glasgow RE, Engelgau MM, Jack L, et al. The effectiveness of disease and case management for people with diabetes. Am J Prev Med 2002;22(4 Suppl):15-38.

12. Tsai AC, Morton SC, Mangione CM, Keeler EB. A meta-analysis of interventions to improve care for chronic illnesses. Am J Manag Care 2005;11(8):478-488.

13. Maciejewski ML, Chen SY, Au DH. Adult asthma disease management: an analysis of studies, approaches, outcomes, and methods. Respir Care 2009;54(7):878-886.

14. Lemmens KM, Nieboer AP, Huijsman R. A systematic review of integrated use of disease-management interventions in asthma and COPD. Respir Med 2009;103(5):670-691. 


\section{Chronic Disease and Care Management Programs for Adults With Asthma}

15. Steuten L, Lemmens K, Vrijhoef B. Health technology assessment of asthma disease management programs. Curr Opinion Allery Clin Immunol 2007;7(3):242-248.

16. Hulscher M, Laurant M, Grol R. Process evaluation of quality improvement interventions. In: Grol R, Baker R, Moss F, editors. Quality improvement research: understanding the science of change in health care. London: BMJ Publishing Group; 2004.

The author has disclosed no conflicts of interest.

Correspondence: Lotte MG Steuten PhD MSc, Department of Health Organization, Policy, and Economics, School for Care and Public Health Research, Maastricht University Medical Centre, Postbox 616, 6200 MD Maastricht, The Netherlands. E-mail: lotte.steuten@ beoz.unimaas.nl.
17. Steuten L, Vrijhoef B, Severens H, Van Merode F, Spreeuwenberg C. Are we measuring what matters in health technology assessments of disease management? Int J Technol Assess Health Care 2006; 22(1):47-57.

18. Gress S, Baan C, Calnan M, Dedeu T, Goenewegen P, Howson H, et al. Co-ordination and management of chronic conditions in Europe: the role of primary care - position paper of the European Forum for Primary Care. Quality in Primary Care 2009;17(1):7586.

19. Steuten L, Palmer S, Vrijhoef B, van Merode F, Spreeuwenberg C, Severens H. Cost-utility of a disease management program for patients with asthma. Int J Technol Assess Health Care 2007;23(2): 184-191.

20. Steuten LMG, Lemmens K, Nieboer A, Vrijhoef HJM. Identifying potentially cost-effective chronic care programmes for people with COPD. Int J COPD 2009;4:87-100.

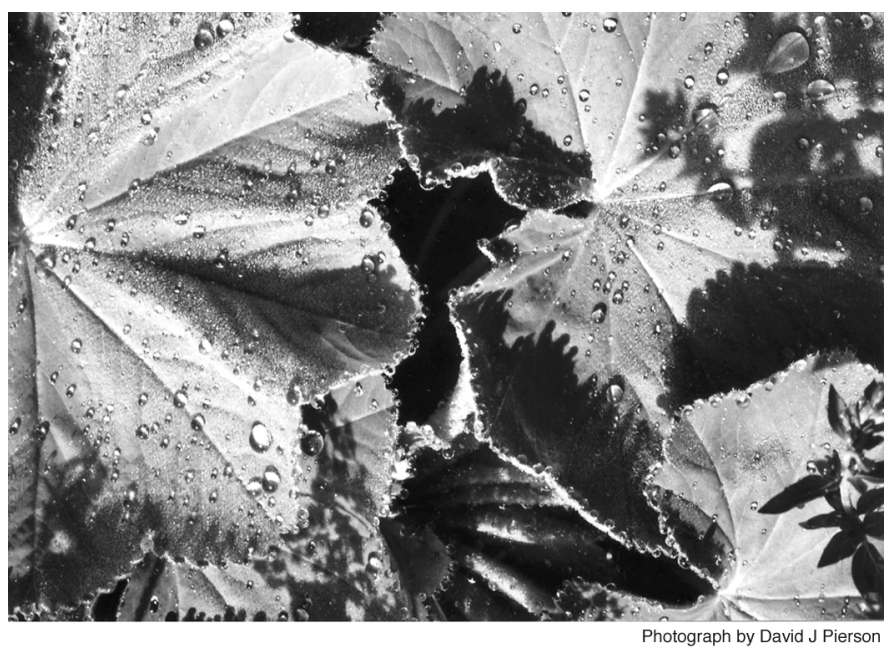

